\title{
Clinical Heterogeneity of Differentiated Thyroid Cancer between Children Less than 10 Years of Age and Those Older than 10 Years: A Retrospective Study of 70 Cases
}

\author{
Yuwei Liu ${ }^{\mathrm{a}}$ Shengcai Wang ${ }^{\mathrm{a}}$ Yanzhen $\mathrm{Li}^{\mathrm{a}}$ Xuexi Zhang ${ }^{\mathrm{a}}$ \\ Zhiyong Liu ${ }^{a}$ Qiaoyin Liu ${ }^{a}$ Nian Sun ${ }^{a}$ Jie Zhang ${ }^{a}$ Wentong Ge ${ }^{a}$ \\ Yongli Guo ${ }^{b}$ Yuanhu Liu ${ }^{a}$ Xiaolian Fang ${ }^{a}$ Tingting Ji ${ }^{a}$ Jun Tai ${ }^{c}$ Xin $\mathrm{Ni}^{\mathrm{a}}{ }^{\mathrm{b}}$ \\ aDepartment of Otolaryngology, Head and Neck Surgery, Beijing Children's Hospital, Capital Medical University, \\ National Center for Children's Health (NCCH), Beijing, China; 'beijing Key Laboratory for Pediatric Diseases of \\ Otolaryngology, Head and Neck Surgery, Beijing Pediatric Research Institute, Beijing Children's Hospital, Capital \\ Medical University, National Center for Children's Health (NCCH), Beijing, China; 'Children's Hospital Capital \\ Institute of Pediatrics, Department of Otolaryngology, Head and Neck Surgery, Beijing, China
}

\section{Keywords}

Childhood thyroid cancer - Papillary thyroid cancer - Clinical outcomes

\begin{abstract}
Objectives: The objectives of this study were to explore the clinical heterogeneity of differentiated thyroid cancer (DTC) between prepubertal children and adolescents and guide clinical treatment. Methods: A retrospective study included patients with DTC aged $\leq 19$ years in Beijing Children's Hospital from June 2014 to June 2019. All patients were enrolled and divided into 2 subgroups based on the threshold age of 10 years, namely the childhood group (CG) ( $\leq 10$ years old); and the adolescent group (AG) (between 10 and 19 years old). The $x^{2}$ test and Fisher's exact test were used to estimate the effect of risk factors in the 2 age groups. Multivariate binary logistic regression models were conducted to assess the recurrent risk factors. Results: Seventy cases of DTC were included with an average age of $9.94 \pm 2.88$ years, including
\end{abstract}

35 in CG and 35 in AG. The most common clinical manifestation was a painless mass in the neck, accounting for $77.1 \%$ (54/70) of patients. Compared with the AG, the CG was more likely to have lymph node metastasis $(p=0.022)$ and distant metastasis $(p=0.041)$. The CG was more likely to have extrathyroidal extension $(p=0.012)$ and had a significantly higher recurrence rate than the AG $(p=0.040)$. Age was an independent variable predictive of recurrence $(p=0.0347)$. Conclusion: Regional invasiveness, cervical lymph node metastasis, and distant metastasis of DTC were more likely to occur in children $\leq 10$ years old. Meanwhile, children $\leq 10$ years old with DTC were more likely to have recurrence than adolescent's postsurgical treatment. Thus, children younger than 10 years of age with DTC should be treated more aggressively.

(C) 2021 European Thyroid Association Published by S. Karger AG, Basel

Yuwei Liu and Shengcai Wang have contributed equally to this work.
Correspondence to:

Jun Tai, trenttj@163.com

Xin Ni, nixin@bch.com.cn 


\section{Introduction}

Thyroid cancer is rare in the childhood period, the incidence in children is much lower than that in adults. In China, the incidence of differentiated thyroid cancer (DTC) in children is about 0.44 cases per $1,00,000$ persons, and the mortality is about 0.02 deaths per $1,00,000$ persons [1]. An analysis based on the surveillance, epidemiology, and end results database and revealed the annual incidence of DTC was 0.54 cases per $1,00,000$ persons in children [2], and it was increasing year by year. Other studies have found that the incidence rates increased by $1.1 \%$ from 1973 to 2006 and by $9.5 \%$ from 2006 to 2013 [3, 4]. In 10 years between 2006 and 2017, the number of hospitalized patients with DTC has increased $>3$-fold in Beijing Children's Hospital [5]. Thyroid carcinoma has even been reported in neonates [6].

The age of the patient has an important impact on survival in many malignant diseases. Whereas the association between age and survival is common for many types of cancer, well-differentiated thyroid cancer is the only malignancy to include age as a part of the American Joint Committee on Cancer staging system, indicating that age at diagnosis has been identified as a major determinant of thyroid cancer-specific survival. Shah et al. [7] found that age at diagnosis was a major determinant of response to therapy and disease-specific survival in adult patients with thyroid carcinoma. For children and adolescents being in a golden period of continuous development and maturity, the effect of age may also be important. However, due to the small sample size in children, previous studies tended to combine the childhood patients with adolescents without considering the variable of age $[8,9]$, which may lead to unreliable information.

Therefore, in the present study, 70 children with DTC treated in our hospital were retrospectively evaluated by age. The same diagnostic and therapeutic techniques were employed for all subjects. We compared the age groups in terms of their clinical presentation, TNM stage, the risk level of recurrence, and other characteristics to provide new insights into clinical diagnosis and treatment for DTC.

\section{Materials and Methods}

Patients and Subgroups

A retrospective study was conducted on DTC patients who first visited Beijing Children's Hospital in past 5 years (from June 2014 to June 2019) and the patients were divided into 2 subgroups. In-
Table 1. Demographic, clinical, and pathologic characteristics of patients included in the present study

\begin{tabular}{|c|c|c|}
\hline \multirow[t]{2}{*}{ Characteristics } & \multicolumn{2}{|c|}{$N=70$} \\
\hline & $n$ & $\%$ \\
\hline \multicolumn{3}{|l|}{ Demographic characteristics } \\
\hline \multicolumn{3}{|l|}{ Age } \\
\hline$\leq 10$ years & 35 & 50.0 \\
\hline$>10$ years & 35 & 50.0 \\
\hline \multicolumn{3}{|l|}{ Sex } \\
\hline Male & 21 & 30.0 \\
\hline Female & 49 & 70.0 \\
\hline \multicolumn{3}{|l|}{ Clinical characteristics } \\
\hline \multicolumn{3}{|l|}{ Presentation at diagnosis } \\
\hline Painless mass & 54 & 77.1 \\
\hline Hoarseness & 8 & 11.4 \\
\hline Asthmatic & 4 & 5.7 \\
\hline Cough & 2 & 2.9 \\
\hline Painful mass & 1 & 1.4 \\
\hline With another tumor & 1 & 1.4 \\
\hline \multicolumn{3}{|l|}{ Surgical procedure } \\
\hline TT & 59 & 84.3 \\
\hline Family history & 4 & 5.7 \\
\hline \multicolumn{3}{|l|}{ Image features } \\
\hline \multicolumn{3}{|l|}{ Primary tumor size } \\
\hline$\leq 2 \mathrm{~cm}$ & 6 & 8.6 \\
\hline $2-4 \mathrm{~cm}$ & 39 & 55.7 \\
\hline$>4 \mathrm{~cm}$ & 25 & 35.7 \\
\hline \multicolumn{3}{|l|}{ Side } \\
\hline Unilateral & 30 & 42.9 \\
\hline Bilateral & 40 & 57.1 \\
\hline Suspicion of cancer by ultrasound & 58 & 82.9 \\
\hline \multicolumn{3}{|l|}{ Pathological characteristics } \\
\hline \multicolumn{3}{|l|}{ T stage } \\
\hline $\mathrm{T} 1$ & 3 & 4.3 \\
\hline $\mathrm{T} 2$ & 16 & 22.9 \\
\hline $\mathrm{T} 3$ & 33 & 47.1 \\
\hline $\mathrm{T} 4$ & 18 & 25.7 \\
\hline \multicolumn{3}{|l|}{$\mathrm{N}$ stage } \\
\hline No & 11 & 15.7 \\
\hline N1 & 59 & 84.3 \\
\hline \multicolumn{3}{|l|}{ M stage } \\
\hline Mo & 55 & 78.6 \\
\hline M1 & 15 & 21.4 \\
\hline \multicolumn{3}{|l|}{ Lymph node metastasis site } \\
\hline Lateral & 45 & 64.3 \\
\hline Central & 55 & 78.6 \\
\hline Hashimoto's thyroiditis & 9 & 12.9 \\
\hline Extrathyroidal extension & 46 & 65.7 \\
\hline
\end{tabular}

TT, total or near-total thyroidectomy. clusion criteria: age $\leq 19$ years; the pathologic diagnosis was DTC; the case data were complete; and thyroid cancer was the first primary malignancy. 
Table 2. Comparison of clinical characteristics of thyroid carcinoma between CG and AG

\begin{tabular}{|c|c|c|c|c|}
\hline Characteristics & CG $(N=35)$ & $\mathrm{AG}(N=35)$ & value & $p$ value \\
\hline \multicolumn{5}{|l|}{ Demographic characteristics } \\
\hline \multicolumn{5}{|l|}{ Gender, $n(\%)$} \\
\hline Male & $12(34.3)$ & $9(25.7)$ & \multirow{2}{*}{0.612} & \multirow{2}{*}{0.434} \\
\hline Female & $23(65.7)$ & $26(74.3)$ & & \\
\hline \multicolumn{5}{|l|}{ Image features } \\
\hline Size, $\mathrm{cm}(\operatorname{mean} \pm \mathrm{SD})$ & $3.54 \pm 1.12$ & $3.52 \pm 1.73$ & 0.057 & 0.954 \\
\hline Suspicion of cancer by ultrasound, $n(\%)$ & $32(91.4 \%)$ & $26(74.3 \%)$ & 3.621 & 0.057 \\
\hline \multicolumn{5}{|l|}{ Pathological characteristics, $n(\%)$} \\
\hline Bilateral & $19(54.3)$ & $21(60.0)$ & 0.233 & 0.629 \\
\hline Extrathyroidal extension & $28(80.0)$ & $18(51.4)$ & 6.341 & $0.012^{*}$ \\
\hline \multicolumn{5}{|l|}{ T stage, $n(\%)$} \\
\hline $\mathrm{T} 1-\mathrm{T} 2$ & $6(17.1)$ & $13(37.1)$ & \multirow{2}{*}{3.540} & \multirow{2}{*}{0.060} \\
\hline $\mathrm{T} 3-\mathrm{T} 4$ & $29(82.9)$ & $22(62.9)$ & & \\
\hline Lymph node metastasis, $n(\%)$ & $33(94.3)$ & $26(74.3)$ & 5.285 & $0.022^{*}$ \\
\hline Distant metastasis, $n(\%)$ & $11(31.4)$ & $4(11.4)$ & 4.158 & $0.041^{*}$ \\
\hline $\mathrm{TT}, n(\%)$ & $33(94.3)$ & $26(74.3)$ & 5.285 & $0.022^{*}$ \\
\hline Lateral, $n(\%)$ & $25(71.4)$ & $20(57.1)$ & 1.556 & 0.212 \\
\hline Central, $n(\%)$ & $30(85.7)$ & $25(71.4)$ & 2.121 & 0.145 \\
\hline
\end{tabular}

CG, childhood group; AG, adolescent group; TT, total or near-total thyroidectomy. ${ }^{*} p<0.05$.

This study was authorized by the Ethics Committee of Beijing Children's Hospital. These patients were diagnosed and treated first in $\mathrm{BCH}$. Data were collected from all patients, including the initial symptoms, TNM stage, risk level, therapy, course, and follow-up results. We also collected clinical data, including the age, gender, onset of symptoms, ultrasound scans, tumor size, histological type, invasion of cervical soft tissues, and local and distant metastases. According to the WHO criteria for defining the age group [10], pediatric patients with DTC were divided into 2 subgroups, the childhood group (CG) for patients younger than 10 years old, and the adolescent group (AG) for patients between 10 and 19 years old.

\section{Postoperative Surveillance}

Patients underwent postoperative surveillance according to risk category as outlined by the ATA guidelines. Recurrence was defined as new evidence of disease detected radiographically by ultrasound or diagnostic whole-body scan occurring $>6$ months after definitive therapy.

\section{Statistical Analysis}

The statistical analyses were performed using SPSS 21.0 for Windows (IBM Corp., Armonk, NY, USA), with the significant statistical threshold of 2 -tailed $p$ value $<0.05$. Summary descriptive statistics were calculated for demographic and disease characteristics. Differences of clinical characteristics in the CG and AG were tested with independent-samples $t$ tests for continuous variables and Pearson's $\chi^{2}$ test or Fisher's exact test was used to examine categorical variables. Multivariate binary logistic regression models were successively conducted to assess the recurrent risk factors.

\section{Results}

The demographic, clinical, and pathologic characteristics of 70 pediatric patients are shown in Table 1. Among the 70 patients, 35 were in CG (aged $\leq 10$ years) and 35 were in AG (10-19 years). The average age of the patients was $9.94 \pm 2.88$ years (ranging from 3.32 to 15.95 years). All patients were diagnosed with PTC. The clinical characteristics between CG and AG were compared (Table 2). The gender proportions of the 2 groups were similar, with no significance difference. The principal symptom at initial diagnosis was a painless mass in the neck (54 cases, 77.1\%). Others reported symptoms included hoarseness (11.4\%), wheezing $(5.7 \%)$, intermittent cough $(2.9 \%)$, neck masses with pain (1.4\%), and 1 case $(1.4 \%)$ suffered multiple endocrine neoplasms. Four patients (5.7\%) had a family history of thyroid tumor of close relatives (i.e., within 3 generations).

All 70 patients underwent ultrasound examination before operation. The average tumor size was $3.53 \pm 1.44 \mathrm{~cm}$, including $3.54 \pm 1.12 \mathrm{~cm}$ in the CG, and $3.52 \pm 1.73 \mathrm{~cm}$ in the AG $(t=0.057, p=0.954)$. There were 58 cases with preoperative ultrasound examination were suspected of thyroid cancer, with a rate of $82.9 \%$ (58/70), including $91.4 \%(32 / 35)$ in the CG, and $74.3 \%(26 / 35)$ in the AG $\left(\chi^{2}=3.621, p=0.057\right)$. The initial treatment protocol included total thyroidectomy and lobectomy. Fifty-nine pa- 
Table 3. Information of 5 children with recurrent laryngeal involvement

\begin{tabular}{lrlllll}
\hline No & $\begin{array}{l}\text { Age, } \\
\text { years }\end{array}$ & Gender & Stage & Reconstruction & $\begin{array}{l}\text { Decannulation, } \\
\text { time }\end{array}$ & Recurrence \\
\hline 1 & 9.74 & F & T4aN1bM1 & Yes & Yes, $6 \mathrm{~m}$ & No \\
2 & 7.06 & M & T4aN1bM1 & Yes & Yes, $11 \mathrm{~m}$ & Yes \\
3 & 12.11 & M & T4aN1bM1 & Yes & Yes, $12 \mathrm{~m}$ & No \\
4 & 5.31 & M & T4aN1bM1 & No & No & No \\
5 & 10.38 & F & T4aN1bM1 & Yes & No & Yes \\
\hline
\end{tabular}

F, female; M, male.

tients $(84.3 \%)$ underwent total thyroidectomy, including $94.3 \%(33 / 35)$ of the CG and $74.3 \%(26 / 35)$ of the AG $\left(\chi^{2}=5.285, p=0.022\right)$. There was bilateral recurrent laryngeal nerve involvement in 5 cases, and 4 cases had a nerve anastomosis after resection of the involved nerve segment. One case had severe bilateral involvement of the recurrent laryngeal nerve at the laryngeal entry point, the surgeon could not track the upper end of the nerve segment, and failed to achieve nerve reconstruction. All 5 patients underwent tracheostomy during operation (Table 3 ).

Of all cases, 9 (12.9\%) were associated with Hashimoto's thyroiditis, including 3 cases in the CG and 6 cases in the AG. At diagnosis, extrathyroidal extension of the tumor was more prevalent in children than in adolescents $(80.0 \%$ vs. $51.4 \% ; p=0.012)$. Bilateral thyroid lobe involvement was manifested in 19 children (54.3\%) and in 21 adolescents $(60.0 \% ; p=0.629)$. The proportions of T1T2 stage in CG and AG were $17.1 \%$ and $37.1 \%\left(\chi^{2}=3.540\right.$, $p=0.060)$, respectively. Cervical lymph node metastasis was more prevalent in CG (94.3\% vs. $74.3 \%$; $p=0.022)$, and distant metastasis (all lung metastases) was also more prevalent in CG (31.4\% vs. $11.4 \%$; $p=0.041)$. There were no significant differences in the central and lateral neck lymph node metastasis between the 2 groups.

Sixty-eight patients $(97.1 \%)$ were followed for a mean follow-up time of $34.2 \pm 18.5$ months (range 7.9-68.3 months). All patients were required to take levothyroxine for life after surgery. Nine patients had transient hoarseness after surgery, and all spontaneously recovered within 6 months of surgery. Among the 5 cases with tracheostomy, 3 cases had successful removal of the tracheal cannula at 6,11 , and 12 months, respectively. One patient was found to have cervical lymph node metastasis 13 months after surgery, requiring reoperation and tracheal cannula. One patient without nerve reconstruction was followed up for more than 2 years with tracheal cannula (Table 3). The prevalence of transient hypocalcemia after

Clinical Heterogeneity of DTC: A

Retrospective Study operation was $45.6 \%(31 / 68)$, of which $50.0 \%(17 / 34)$ were in the CG and $41.2 \%(14 / 34)$ were in the AG $\left(\chi^{2}=\right.$ $0.534, p=0.465)$. The incidence of postoperative permanent hypoparathyroidism was $2.9 \%(2 / 68)$, both of which were in the CG. Fifty-four patients $(79.4 \%)$ were treated with ${ }^{131} \mathrm{I}$ after operation, of which $91.2 \%$ were $(31 / 34)$ in CG and $67.7 \%(23 / 34)$ were in AG $\left(\chi^{2}=5.757, p=0.016\right)$. The average frequency of radioiodine treatments in this group was 1.35 times (range, $0-6$ times).

The recurrence rate was $14.7 \%(10 / 68)$, and the average recurrence time was 47.5 months (range 12.6-68.3 months). The number of recurrences was $10(80.0 \%)$ in the CG and $2(20.0 \%)$ in the AG. The recurrence rates differed significantly among the age groups $\left(\chi^{2}=4.221, p=\right.$ 0.040 ). Recurrence rates differed significantly among the primary tumor size $(t=-2.011, p=0.048)$. The number of extrathyroidal extension differed significantly in the recurrence group and nonrecurrence group $\left(\chi^{2}=4.352\right.$, $p=0.037)$. And the number of distant metastasis also differed significantly in the recurrence group and nonrecurrence group $\left(\chi^{2}=14.144, p<0.001\right)$. Significant differences were not observed in gender, bilateral tumor, Hashimoto's thyroiditis, T stage, lymph node metastasis, total or near-total thyroidectomy, central and lateral neck metastasis, ${ }^{131} \mathrm{I}$ - treatment, and cervical lymph node resection between the recurrence and nonrecurrence groups (Table 4). In multivariate analyses, distant metastasis and extrathyroidal extension were adjusted, and age $(\mathrm{OR}=0.133,95 \% \mathrm{CI}=0.021-0.865 ; p=0.0347)$ was an independent variable predictive of recurrence (Table 5).

\section{Discussion}

In adults, the tumor size is one of the most important factors to influence treatment and prognosis [11]. The data suggest that there is a relationship between the risk 
Table 4. Comparison of clinical characteristics of thyroid carcinoma between CG and AG

\begin{tabular}{|c|c|c|c|c|}
\hline Characteristics & $\begin{array}{l}\text { Recurrence } \\
(N=10)\end{array}$ & $\begin{array}{l}\text { Nonrecurrence } \\
(N=58)\end{array}$ & value & $p$ value \\
\hline \multicolumn{5}{|l|}{ Age, $n(\%)$} \\
\hline$\leq 10$ years & $8(80.0)$ & $26(44.8)$ & 4.221 & $0.040^{*}$ \\
\hline$>10$ years & $2(20.0)$ & $32(55.2)$ & & \\
\hline \multicolumn{5}{|l|}{ Gender, $n(\%)$} \\
\hline Male & $4(40.0)$ & $16(27.6)$ & 0.176 & 0.675 \\
\hline Female & $6(60.0)$ & $42(72.4)$ & & \\
\hline Primary tumor size, $\mathrm{cm}($ mean $\pm \mathrm{SD})$ & $3.36 \pm 1.43$ & $4.34 \pm 1.31$ & -2.011 & $0.048^{*}$ \\
\hline Bilateral, $n(\%)$ & $8(80.0)$ & $31(53.4)$ & 1.493 & 0.222 \\
\hline Hashimoto's thyroiditis, $n(\%)$ & $0(0.0)$ & $9(15.5)$ & 0.692 & 0.405 \\
\hline Extrathyroidal extension, $n(\%)$ & $10(100.0)$ & $35(60.3)$ & 4.352 & $0.037^{*}$ \\
\hline \multicolumn{5}{|l|}{ T stage, $n(\%)$} \\
\hline $\mathrm{T} 1-\mathrm{T} 2$ & $0(0.0)$ & $19(32.8)$ & 3.065 & 0.080 \\
\hline T3-T4 & $10(100.0)$ & $39(67.2)$ & & \\
\hline Lymph node metastasis, $n(\%)$ & $10(100.0)$ & $47(81.0)$ & 1.080 & 0.299 \\
\hline Distant metastasis, $n(\%)$ & $7(70.0)$ & $7(12.1)$ & 14.144 & $<0.001^{*}$ \\
\hline $\mathrm{TT}, n(\%)$ & $10(100.0)$ & $47(81.0)$ & 1.080 & 0.299 \\
\hline Lateral, $n(\%)$ & $8(80.0)$ & $36(62.1)$ & 0.544 & 0.461 \\
\hline Central, $n(\%)$ & $10(100.0)$ & $43(74.1)$ & 1.984 & 0.159 \\
\hline${ }^{131} \mathrm{I}$ - treatment, $n(\%)$ & $10(100.0)$ & $44(75.9)$ & 1.742 & 0.187 \\
\hline
\end{tabular}

CG, childhood group; AG, adolescent group; TT, total or near-total thyroidectomy. ${ }^{*} p<0.05$.

Table 5. Multivariate logistic regression analyses of recurrence

\begin{tabular}{lrlllll}
\hline Variable & $\beta$ & SE & Wald & $p$ value & OR & $95 \%$ CI \\
\hline Age & -2.0148 & 0.9539 & 4.4610 & $0.0347^{*}$ & 0.133 & $0.021-0.865$ \\
Bilateral & 1.1521 & 0.8875 & 1.6851 & 0.1942 & 3.165 & $0.556-18.023$ \\
Primary tumor size & 0.5506 & 0.2904 & 3.5959 & 0.0579 & 1.734 & $0.982-3.064$ \\
\hline$* 0<0.05$. & & & & & \\
\hline
\end{tabular}

of disease progression and tumor size, namely, that the risk of disease starts to increase from a tumor with a diameter $>1 \mathrm{~cm}$. Unfortunately, there are no data in children. Considering that children are in the process of growth and development, the volume of the thyroid itself changes significantly with age. Previous studies have suggested that a tumor size of $10 \mathrm{~mm}$ in adults is equivalent to a tumor size of $4 \mathrm{~mm}$ in a 10 -year-old child. The younger the age, the greater the extent of tumor involvement [12]. Pazaitou-Panayiotou et al. [13] observed a negative correlation between the tumor size and age, after grouping by age. However, this opinion is still controversial [14]. In our study, the difference in the tumor size of a single lesion between the 2 age groups was not significant. Since more than half of patients had multifocal disease, whether the size of a single lesion is indeed instructive for treatment decisions in DTC remains to be further assessed.

Previous studies have shown that the course of DTC in children is different from that in adults, and its biological characteristics are closely related to age. DTC in children is more prone to cervical lymph node metastasis and lung metastasis than that in adult $[13,15]$. The incidence of lymph node metastasis is $50-90 \%$, and the incidence of distant metastasis is $6-33 \%$ in children [16-18]. The rate of cervical lymph node metastasis and distant metastasis in our study is 84.3 and $21.4 \%$, respectively, in agreement with the results of the previous studies. Comparing the 2 subgroups, we also found that DTC in children was more likely to have extrathyroidal invasion than that in adoles- 
cents, and it was more prone to lymph node metastasis and distant metastasis. In our previous study, our research team has found that RPL5 and KDM4 have significant differences in the expression of PTC tissues in children and adults $[19,20]$. Cordioli et al. [21] found that the expression of the thyroid specific gene, sodium iodide symporter protein, was a good predictor of prognosis, and was expressed differently between children and adolescents. This suggest that the molecular mechanism of PTC at different ages is different. However, its specific mechanism remains to be further studied.

Considering that the majority of pediatric patients has bilateral and multifocal disease (30 and 65\%, respectively) $[22,23]$, an increased risk for recurrence and subsequent second surgical procedures will occur when less than a near-TT or TT is performed [22, 24]. In a long-term analysis of 215 pediatric patients with PTC, bilateral lobar resection compared with lobectomy was shown to decrease the incidence of local recurrence from 35 to $6 \%$ over a 40 -year follow-up [24]. Therefore, for children with thyroid nodules and DTC, management guidelines issued by the American Thyroid Association recommended total thyroidectomy [25]. In our study, $84.3 \%$ of patients underwent total thyroidectomy, 11 patients in our group underwent thyroid lobectomy plus isthmus resection. Among them, 5 cases were diagnosed as thyroid adenomas by preoperative ultrasound, FNA, and intraoperative freezing, but the paraffin section after surgery found cancer. In another 7 cases, the tumor size was $<4 \mathrm{~cm}$, there was no lymph node metastasis found in the preoperative evaluation, and the parents or guardian requested to a retain part of the thyroid. Significant differences were not observed in total thyroidectomy and lobectomy between the recurrence and non-recurrence groups. Based on the results of this study, we believe that for some cases of unilateral small lesions, tumors limited to the gland, and with no neck lymph node metastasis, lobectomy plus isthmus resection is an option if the guardians have a strong desire to retain a part of the thyroid, but more critical postoperative follow-up will be required. It should be pointed out that there were only 11 cases of lobectomy plus isthmus resection in our group, and there was not enough prospective evidence to support it. Therefore, regarding the choice of operation, it is necessary to continue to improve the relevant evidence in the future.

There is still no consensus on the need for preventive central lymph node dissection in children with no evidence of extrathyroidal invasion and/or local metastasis. In our study, no postoperative recurrence was detected in the children who did not undergo prophylactic cervical neck dissection. The main reason is that these patients all had a low T stage, without cervical lymph node metastasis by preoperative evaluation. For patients with early stage metastasis and no lymph node metastasis, guidelines on whether to perform prophylactic lymph node dissection and how to balance the risks and benefits need to be addressed in a larger case study.

Studies have shown that the recurrence rate of DTC in children can reach $35-47 \%[26,27]$. In our study, the recurrence rate was $14.7 \%(10 / 68)$, which was lower than previous reports. The main reason may be that $84.3 \%$ of the patients in our group underwent total thyroidectomy and cervical neck dissection. In addition, the study suggests that most children recur within 5 years of diagnosis, but a few patients recur after 10 years or more [24]. The average follow-up time in our study was 34.2 months, with a minimum of only 7.9 months, suggesting that some cases still have the possibility of future recurrence. Studies have compared the prognosis of DTC at different ages, and most results concurs that age is associated with persistence and/or recurrence of the disease [28]. In our study, the comparison between the 2 groups found a greater rate of recurrence in children than in adolescents. In multivariate analyses, age was an independent variable predictive of recurrence. Therefore, for younger patients, the scope of surgical options should be more aggressive, and more attention should be paid to the follow-up.

Because patients with DTC are younger and have longer postoperative survival time, surgical complications have a greater impact on the quality of life than adults, which is a key issue to be considered in treatment. Additionally, compared with adults, the incidence of surgical complications in children is higher $[29,30]$. Recurrent laryngeal nerve injury is one of the main surgical complications. The incidence of permanent recurrent laryngeal nerve injury is $0-6.2 \%[28,31-35]$. It is consistent with our study. Studies reported that the incidence of permanent recurrent laryngeal nerve injury was negatively correlated with the age of pediatric patients [29]. Surgery in children is associated with a higher risk of recurrent laryngeal nerve injury due to increased aggressiveness, extensive infiltration, and greater vulnerability to recurrent laryngeal nerve injury, as well as the relatively difficult intraoperative identification due to the small size of the recurrent laryngeal nerve in young children. The intraoperative tracheostomy decision is based on several factors: recurrent laryngeal nerve palsy, radiological evidence of tracheal compromise in addition to the intraoperative findings of tracheal deformity, and adherence or invasion by thyroid tissues. In our study, when the recurrent laryn- 
geal nerve was found to be involved bilaterally by tumor during surgery, prophylactic tracheostomy was performed. Therefore, the possibility of recurrent laryngeal nerve involvement should be fully considered before surgery, and both patients and physicians should be prepared for nerve reconstruction and tracheostomy.

\section{Conclusion}

Compared with previous studies, the sample size of the younger children in this study is larger, and the structure among the age groups of the children is more reasonable. As such, the conclusions about the age-related clinical heterogeneity of the children are more reliable. However, long-term follow-up is still needed to further understand the influence of age on the clinical characteristics and prognosis of pediatric thyroid cancer. It is generally believed that young patients with tumors tend to have worse prognoses due to tumor biology, including a more aggressive tumor at a later stage. The biological behavior, clinical characteristics, and prognosis of thyroid cancer are all related to age. Our results may provide arguments for consideration of the fact that the surgical treatment in younger patients ( $\leq 10$ years) may be needed to be given more aggressively than in older children or in adults. This must be further studied in future cohorts. The complications of DTC in children are higher, and the surgery should be performed more carefully. Pediatric thyroid surgery should be performed in a hospital with the full spectrum of pediatric specialty care, to include, but not be limited to endocrinology, radiology (US and anatomic imaging), nuclear medicine, anesthesia, a high-volume thyroid surgeon, and intensive care. Most guidelines for
DTC treatment recommend total thyroidectomy and aggressive cervical lymph node dissection. However, for some early stage patients without lymph node metastasis, the relationship between type of surgery and outcome still needs to be confirmed based on evidence.

\section{Statement of Ethics}

The study was conducted in accordance with the principles of the Declaration of Helsinki, and the study protocol was approved by the Ethics Committee of Beijing children's hospital (the reference number: 2019-k-400). We obtained written parental consent for the minors before the study was begun.

\section{Conflict of Interest Statement}

The authors have no conflicts of interest to disclose.

\section{Funding Sources}

This work was supported by Beijing Hospitals Authority' Ascent Plan (DFL20191201) and Beijing Hospitals Authority Youth Programme (QML20181202).

\section{Author Contributions}

Yuwei Liu, Shengcai Wang, Jun Tai, and Xin Ni conceived and designed the work; Yuwei Liu and Shengcai Wang wrote the article; Jie Zhang, Wentong Ge, and Yongli Guo revised it critically for important intellectual content; Yanzhen Li, Xuexi Zhang, Zhiyong Liu, Qiaoyin Liu, and Nian Sun collected data; Yuanhu Liu, Xiaolian Fang, and Tingting Ji analyzed the data; Shengcai Wang and Xin Ni were funding acquisition.

\section{References}

1 Yang L, Zheng R, Wang N, Zhang S, Chen W. (Analysis of incidence and mortality of thyroid cancer in China, 2010). Zhonghua Yu Fang Yi Xue Za Zhi. 2014;48(8):663-8.

2 Hogan AR, Zhuge Y, Perez EA, Koniaris LG, Lew JI, Sola JE. Pediatric thyroid carcinoma: incidence and outcomes in 1,753 patients. J Surg Res. 2009;156(1):167-72.

3 Pellegriti G, Frasca F, Regalbuto C, Squatrito $\mathrm{S}$, Vigneri R. Worldwide increasing incidence of thyroid cancer: update on epidemiology and risk factors. J Cancer Epidemiol. 2013; 2013:965212.
4 Qian ZJ, Jin MC, Meister KD, Megwalu UC. Pediatric thyroid cancer incidence and mortality trends in the United States, 1973-2013. JAMA Otolaryngol Head Neck Surg. 2019; 145(7):617-23.

5 Wang JL, Ren XY, Ni X, Tai J, Gong CX. (Clinical analysis of thyroid cancer in 62 children). Zhonghua Er Ke Za Zhi. 2018;56(8): 597-600.

6 Hung W, Sarlis NJ. Current controversies in the management of pediatric patients with well-differentiated nonmedullary thyroid cancer: a review. Thyroid. 2002;12(8):683.

7 Shah S, Boucai L. Effect of age on response to therapy and mortality in patients with thyroid cancer at high risk of recurrence. J Clin Endocrinol Metab. 2018;103(2):689-97.
8 Rubinstein JC, Herrick-Reynolds K, Dinauer C, Morotti R, Solomon D, Callender GG, et al. Recurrence and complications in pediatric and adolescent papillary thyroid cancer in a high-volume practice. J Surg Res. 2020;249: 58-66.

9 Jain NK, Mostoufi-Moab S, Hawkes CP, Nelson ND, Surrey LF, Jones ZS, et al. Extrathyroidal extension is an important predictor of regional lymph node metastasis in pediatric differentiated thyroid cancer. Thyroid. 2020 Jul;30(7):1037-43.

10 Global World Health Organisation. Accelerated Action for the Health of Adolescents (AA-HA): guidance to support country implementation. Geneva; 2017. 
11 Kamran SC, Marqusee E, Kim MI, Frates MC, Ritner J, Peters H, et al. Thyroid nodule size and prediction of cancer. J Clin Endocrinol Metab. 2013;98(2):564-70.

12 Rivkees SA, Mazzaferri EL, Verburg FA, Reiners C, Luster M, Breuer CK, et al. The treatment of differentiated thyroid cancer in children: emphasis on surgical approach and radioactive iodine therapy. Endocr Rev. 2011; 32(6):798-826.

13 Pazaitou-Panayiotou K, Iliadou PK, Mandanas S, Vasileiadis T, Mitsakis P, Tziomalos K, et al. Papillary thyroid carcinomas in patients under 21 years of age: clinical and histologic characteristics of tumors $\leq 10 \mathrm{~mm}$. J Pediatr. 2015;166(2):451-6.

14 Farahati J, Reiners C, Demidchik EP. Is the UICC/AJCC classification of primary tumor in childhood thyroid carcinoma valid? J Nucl Med. 1999;40(12):2125.

15 Galuppini F, Vianello F, Censi S, Barollo S, Bertazza L, Carducci S, et al. Differentiated thyroid carcinoma in pediatric age: genetic and clinical scenario. Front Endocrinol. 2019; 10:552.

16 Spinelli C, Tognetti F, Strambi S, Morganti R, Massimino M, Collini P. Cervical lymph node metastases of papillary thyroid carcinoma, in the central and lateral compartments, in children and adolescents: predictive factors children and adolescents: predictive factors. World J Surg. 2018;42(8):2444-53.

17 Vaisman F, Bulzico DA, Pessoa CH, Bordallo MA, Mendonça UB, Dias FL, et al. Prognostic factors of a good response to initial therapy in children and adolescents with differentiated thyroid cancer. Clinics. 2011;66(2):281-6.

18 Zimmerman D, Hay ID, Gough IR, Goellner JR, Ryan JJ, Grant CS, et al. Papillary thyroid carcinoma in children and adults: long-term follow-up of 1,039 patients conservatively treated at one institution during three decades. Surgery. 1988;104(6):1157.

19 Jin YQ, Wang SC, Tai J, Zhang J, Chen F, Shi $\mathrm{J}$, et al. (The difference expression and diagnostic value of RPL5 in papillary thyroid carcinoma of children and adults). Zhonghua Er Bi Yan Hou Tou Jing Wai Ke Za Zhi. 2017; 52(11):830-4.
20 Jin YQ, Feng L, Chu P, Zhang J, Tai J, Han Y, et al. Expression and diagnostic value of $\mathrm{KD}$ M4A in papillary thyroid carcinoma of children and adults. J Chin.Oncol. 2016;22(10): 838-43.

21 Cordioli MI, Moraes L, Alves MT, Delcelo R, Monte O, Longui CA, et al. Thyroid-specific genes expression uncovered age-related differences in pediatric thyroid carcinomas. Int J Endocrinol. 2016;2016:1956740-9.

22 Handkiewicz-Junak D, Wloch J, Roskosz J, Krajewska J, Kropinska A, Pomorski L, et al. Total thyroidectomy and adjuvant radioiodine treatment independently decrease locoregional recurrence risk in childhood and adolescent differentiated thyroid cancer. J Nucl Med. 2007;48(6):879-88.

23 Jarzab B, Handkiewicz Junak D, Włoch J, Kalemba B, Roskosz J, Kukulska A, et al. Multivariate analysis of prognostic factors for differentiated thyroid carcinoma in children. Eur J Nucl Med. 2000;27(7):833-41.

24 Hay ID, Gonzalez-Losada T, Reinalda MS, Honetschlager JA, Richards ML, Thompson GB. Long-term outcome in 215 children and adolescents with papillary thyroid cancer treated during 1940 through 2008. World J Surg. 2010;34(6):1192-202.

25 Scholz S, Smith JR, Chaignaud B, Shamberger RC, Huang SA, et al. Thyroid surgery at children's hospital Boston: a 35-year single-institution experience. J Pediatr Surg. 2011;46(3): 437-42.

26 Sugino K, Nagahama M, Kitagawa W, Shibuya $\mathrm{H}$, Ohkuwa K, Uruno T, et al. Papillary thyroid carcinoma in children and adolescents: long-term follow-up and clinical characteristics. World J Surg. 2015;39(9):2259-65.

27 Astl J, Chovanec M, Lukeš P, Katra R, Dvořáková $\mathrm{M}$, Vlček $\mathrm{P}$, et al. Thyroid carcinoma surgery in children and adolescents 15 years experience surgery of pediatric thyroid carcinoma. Int J Pediatr Otorhinolaryngol. 2014;78(7):990-4.
28 Demidchik YE, Demidchik EP, Reiners C, Biko J, Mine M, Saenko VA, et al. Comprehensive clinical assessment of 740 cases of surgically treated thyroid cancer in children of Belarus. Ann Surg. 2006;243(4):525-32.

29 Francis GL, Waguespack SG, Bauer AJ, Angelos P, Benvenga S, Cerutti JM, et al. Management guidelines for children with thyroid nodules and differentiated thyroid cancer. Thyroid. 2015;25(7):716-59.

30 van Santen HM, Aronson DC, Vulsma T, Tummers RF, Geenen MM, de Vijlder JJ, et al. Frequent adverse events after treatment for childhood-onset differentiated thyroid carcinoma: a single institute experience. Eur J Cancer. 2004;40(11):1743-51.

31 Giordano D, Valcavi R, Thompson GB, Pedroni C, Renna L, Gradoni P, et al. Complications of central neck dissection in patients with papillary thyroid carcinoma: results of a study on 1,087 patients and review of the literature. Thyroid. 2012;22(9):911-7.

32 Baumgarten HD, Bauer AJ, Isaza A, Mostoufi-Moab S, Kazahaya K, Adzick NS, et al. Surgical management of pediatric thyroid disease: complication rates after thyroidectomy at the children's hospital of philadelphia highvolume pediatric thyroid center. J Pediatr Surg. 2019;54(10): 1969.

33 Alkhars A, Abouzayd M, Rouf C, Lardy H, Bakhos D, Pondaven-Letourmy S, et al. Pediatric thyroid surgery: experience in 75 consecutive thyroidectomies. Eur Arch Otorhinolaryngol. 2019;276(1):217-22.

34 Bussières V, Roy S, Deladoey J, Rousseau É, St-Vil D, Piché N, et al. Pediatric thyroidectomy: Favorable outcomes can be achieved by a multidisciplinary team of pediatric providers. J Pediatr Surg. 2019 Mar;54(3):52730.

35 Loyo M, Tufano RP, Gourin CG. National trends in thyroid surgery and the effect of volume on short-term outcomes. Laryngoscope. 2013;123(8):2056-63. 